\title{
Pre-University OUTREACH THROUGH A SPACE CAMP AND A KIRKNESS DISCOVERY CAMP
}

\author{
Witold Kinsner ${ }^{1}$, Nusraat Masood ${ }^{2}$, Randy Herrmann ${ }^{3}$, \\ Mohamed Nasri ${ }^{1}$, Hieu Van Dang ${ }^{1}$, and Kathryn Marcynuk ${ }^{1}$ \\ Cognitive Systems Laboratory \\ ${ }^{1}$ Department of Electrical and Computer Engineering \\ ${ }^{2}$ Women in Science and Engineering \\ ${ }^{3}$ Engineering Access Program \\ University of Manitoba, Winnipeg, MB, Canada R3T 5V6 \\ witold.kinsner@umanitoba.ca
}

\begin{abstract}
Attracting high-school students to science, technology, engineering and mathematics (STEM) should be easy today, but it is not in practice. Universities and organizations such as the Institute of Electrical and Electronics Engineers (IEEE) have invested much effort and implemented many useful mechanisms to increase the enrollment, including open house events, teaching teachers days, IEEE's Teachers In Service Program (TISP), IEEE's Engineering Projects in Community Service (EPICS), as well as IEEE's TryEngineering, TryComputing, and TryNano. We have developed a number of new initiatives to address the problem in Manitoba, and feel that the approach can be used elsewhere.

This paper describes two such initiatives: a space camp for high-school students grade 9 to 11, and the Verna Kirkness Program (VKP) discovery camp for Indigenous high-school students. The first camp was offered several times already, while the second camp was delivered for the first time in 2013.
\end{abstract}

Keywords: Outreach for engineering; student hands-on activities; rocket building; robot building; radio communications; research for students.

\section{INTRODUCTION}

Recent developments in science, technology, engineering and mathematics (STEM) over the last several decades have made it possible to transform technology from machine-oriented (designed to increase productivity and quantification) to more human-centric (to simplify interaction with technology and improve the well-being of individuals). The familiarity of students with technology and its implications should be very conducive to attract talented high-school students to STEM easily, but it is not in practice.

Universities and organizations such as the Institute of Electrical and Electronics Engineers (IEEE) have invested much effort and implemented many useful mechanisms to increase the enrolment, including open house events, teaching teachers days [1], IEEE's Teachers In Service Program (TISP), IEEE's Engineering Projects in Community Service (EPICS), as well as IEEE's TryEngineering, TryComputing, and TryNano. This paper describes two such initiatives at the University of Manitoba: a space camp for high-school students in grade 9 to 11 , and the Verna Kirkness Program (VKP) camp for Indigenous high-school students. The first camp was offered several times already [2], while the second camp was delivered for the first time in 2013.

Both the space and VKP camps are designed to satisfy several long-term objectives, including: (a) to understand the engineering design process, and how ideas can be implemented in a smart way; (b) to learn how to work in teams; (c) to understand how the very-high level of science and engineering developed for space can be applied to our planet; (d) to understand the relationship between our planet and space; and (e) how to be good stewards of this planet.

This paper presents a summary of the experience gained from several camp sessions. Support from over 20 organizations will be reviewed, including a strong Manitoba aerospace industry, the amateur radio community, and several schools. Pedagogical, organizational, and safety issues will be discussed. Linkages to other elements in our aerospace educational program will be made, including a university mentorship for high-school students that extends beyond the camps.

\section{The Space Camp}

\subsection{Motivation}

In the past, outer space was reserved for very few. Today, many more students can find challenging opportunities in space-related education and jobs. Another motivation for engaging in space is that it requires solutions 
to extreme challenges such as a very low pressure, very high radiation, very low and very high temperature, no convection cooling, extreme accelerations and vibrations, to name a few.

In order to provide a place to explore such opportunities, an inexpensive one-week summer space camp (SSC) has been developed at the University of Manitoba (UofM) for high-school students from Manitoba and elsewhere, as one element in our multi-facet spacerelated education program. The purpose of the SSC is to encourage young men and women from high schools to engage in science, engineering and technology. The key reason for the camp is to engage the students in problem identification, problem solving, design, modelling, implementation, verification, and testing in extreme environments. The SSC participants can experience science and engineering through hands-on workshops, short tutorials, and outdoors activities.

\subsection{Overview of Activities}

Typical activities include: rocket building and launching (small and large); robot building and testing; high-altitude balloon launching; amateur radio operations and use for tracking of payloads; satellite ground station operation; fox hunting (transmitter locating); young engineers' satellite (YES2) and zero-G experiment; CubeSat design experience; Canadian Satellite Design Challenge (T-Sat) at the UofM; unmanned vehicles at UofM; simulation of orbital mechanics; demonstration of six high-technology labs at the Faculty of Engineering; space law; astronomy; industrial aerospace accomplishments (Magellan-Bristol); and small space business. The students have access to a multi-million dollar space related software for simulation and exploration.

Launching, tracking and recovering of a near-space balloon with a recoverable payload is done one day after the camp. Launching of a large rocket is done after the camp. Parents are also invited to participate in some of the activities.

\subsection{Logistics}

Each space camp organization takes approximately one year. The SSC director prepares the basic structure of the camp and its timing (normally in the middle of July). The program sheet is discussed by many parties, and its improvements continue to the last day before the camp.

The management group, the Women in Science and Engineering (WISE) provides input on the proposal and develops an advertising brochure, together with a number of workshops, presentations and other activities in high schools to attract the students to the camp. Space camp guides are also selected early, and are required to

CEEA Conf. 2014; Paper 114

Canmore, AB; June 8-11, 2014 participate in the workshops and advertising activities in the high schools.

WISE also maintains a Web site for the interested students to register for the space camp. The fee is maintained at the lowest possible level to allow all students equal access to the events.

Sponsorship is elicited from various educational institutions, research and development institutes, government organizations, space-related companies, businesses, and other groups such as the radio community.

The instructors for each space camp are selected based on their knowledge in the field, technical and communication skills, ability to deliver in time, and the ability to follow up on events after the camp.

All the equipment used in the camp is verified for its functionality, operability, and safety. The parts used in the camp are ordered from reliable sources.

Facilities are booked well in advance to accommodate all the students in one place. We use a large room that is used for design courses during the academic year and in the summer. The room has round tables for group design and interaction, two projection screens that can be operated independently, large windows to allow much day light throughout the day.

Although the camp is designed for education, experiential learning and fun, its activities are very intense, starting from 8:00 AM and ending at 5:00 PM, with 30 minutes for lunch.

\subsection{Specific Space Camp Activities}

This section provides a summary of the main activities, grouped according to the topic, and not the time when they are delivered. However, the delivery sequence of the activities must also be crafted well in order to maintain the students' interest, through diversity of exposure to the topics and instructors.

An example of the 2013 space camp schedule is attached in Appendix A.

2.4.1 Pre-Camp Workshop for TAs: Since soldering of delicate circuits is used during the camp, a separate workshop is offered to the students who become teaching assistants (TAs) during the camp. The TAs are solicited from graduate students and proven undergraduate students. The TAs are also selected based on their technical and communication skills.

2.4.2 Pre-Camp Course: This course was developed by the Canadian Department of Defence, and made available to the SSC participants. It includes the following topics: (i) the space environment, (ii) satellite design, (iii) orbital mechanics, (iv) satellite communcations, (v) satellite navigation, (vi) remote sensing from space, (vii) model rockets, and (viii) space station, ISS. The course was available to the students a month in advance though a 
secure access. The course is undergoing revisions at this time, and is not available to the students.

2.4.3 Pre-Camp Orientation Session: This session took place a day before the camp, and included the parents, guardians and friends of the registered participants. The objective of the session was to describe the goal of the camp, its schedule, and anticipated outcomes not only to the students but also to their parents so that they could provide encouragements and support throughout the week and after the camp. Some parents were not happy about this because the session took place on Sunday, thus cutting their summer cottage plans.

2.4.4 Ice Breaker: This event was recently introduced in order to bring the students together, get them introduced to one another, and prepare them for the activities of the week.

2.4.5 Introduction to Space: Several talks from different speakers provided a motivation for space interests, and some projects in Manitoba high schools, including the highaltitude-balloons, amateur radio in the International Space Station (ARIIS). Projects at the UofM were also discussed, including the Young Engineers' Satellite( YES2) and the zero-gravity experiment in Bordeaux, France. The role of amateur radio to the space projects was also discussed, with a demo of the UofM satellite ground station (SGS).

2.4.6 Rocket Building 1: Rocket building workshops constitute one of the pillars of the space camp. Each student constructs a rocket from a supplied kit, under the supervision of an experienced instructor. Since the construction requires time, the workshop is split into two parts on the first day, and is followed by another part the following day. Each rocket is tested for flight readiness, and is launched from a safe field. To speed up the launching, we start from single rockets, and then move to two-rocket synchronized launches. Each rocket is retrieved and tested.

2.4.7 Rocket Building 2: The first several workshops on rocket building were designed to establish a set of skills for the students that are necessary to appreciate the structure and dynamics of rockets. The second set of workshops was developed to learn how to design and build a larger rocket. Researchers from a composite-materials institute in Manitoba designed the rocket from composite materials, and developed a protocol to implement it safely during the space camp. This project was also a great success, even though the rockets were not intended for a flight, because the students gained experience not available in high schools. .

2.4.8 Robot Building: This is another pillar of the space camp. Since most of the participants were never exposed to soldering, a workshop on small circuit assembly precedes the robot building workshop. The workshop has many TAs to assist each students throughout the assembly. Safety is emphasised at all times. The circuit is a small two-LED blinker. Each completed circuit is tested and taken home by the students.

The robot is based on a solar engine, driving two tiny motors (taken from the vibrating element in a smart phone). The assembly requires many steps, and is guided by the instructor and individually by the TAs. Each robot is tested for operation in the room. If it is not functional, it is fixed either immediately, or before to following day by the TAs. Each robot is tested outdoors in real sun. The distance travelled is measured, and the best robots are later recognized with awards.

2.4.8 Computing for Space: Two workshops were designed to show the students how to design for space. Arduino was used to program various tasks and experiment with various options.

2.4.9 STK Demo: This workshop concentrated on the modelling of orbital mechanics with the help of the STK system, and was conducted by an instructor from the Canadian Forces School of Aerospace Studies (CFSAS).

2.4.10 Satellite Tracking: A payload with a beacon was placed on a car that travelled along the city perimeter, and was tracked by our satellite ground station. The camp participants operated the station, and communicated with other groups in the control room by amateur radio. Licensed hams supervised the activities. This tracking project has been used to establish the electromagnetic ground profile that is useful to determine the actual horizon at which low-Earth-orbit (LEO) satellites could be acquired.

2.4.11 Fox Hunt: A hidden transmitter was located on the campus, and the objective was to find it using radio receivers only by triangulation. The students were separated into teams, and the team that found it first was considered a winner. The strategies used in the hunt were discussed in a debriefing session.

2.4.12 Nano-satellite Project: The UofM has been involved in a project to design, build and test a functional nanosatellite. The project resulted in the first-generation satellite, T-Sat1, in 2012, and second-generation, T-Sat2, in 2014 [3]. Students from the projects demonstrate some aspects of the satellite at the Space Camp.

2.4.13 Other Space Talks: The students had an opportunity to listen to many talks during the camp, including: (i) astronomy, (ii) space law, (iii) space business, (iv) satellite and UAV navigation and communications [4], (v) Magellan-Bristol in space (the rockets used by NASA from Churchill, Manitoba), and (vi) other car design competitions at the UofM. 
2.4.14 Research Lab Demonstrations: Six research lab tours were organized for the students, including: (i) industrial robotics, (ii) robotic walkers, (ii) biomedical robotics and control, (iv) biomedical engineering, (v) nanofabrication, and (vi) rapid prototyping through 3D printing. These lab tours were provided by enthusiastic researchers engaged directly in the labs.

2.4.15 Meet an Astronaut: The previous space camps were successful in arranging a Canadian astronaut to talk to the students. The students prepared and discussed questions for the astronaut, and then the questions were vetted by the instructors at the CFSAS, before being submitted to the Canadian Space Agency (CSA) for their final approval.

In 2013, the students talked to a recent graduate student who had been accepted to the International Space University (ISU) in France. He was the Project Lead for the T-Sat1 a year earlier, and participated in the previous space camps. The connection to France was made through Skype.

\section{The Discovery CAMP}

The UofM has developed a very good Engineering Access Program (ENGAP) for Indigenous high-school students to simplify their access to the Faculty of Engineering. The program is also very helpful to the students already in Engineering.

For the first time in 2013, a one-week Discovery Camp for Indigenous students was developed and administered through ENGAP under the umbrella of the Verna Kirkness Program (VKP) in the Faculty of Engineering. This activity is intended to engage Indigenous students in our research programs. Seventeen students were selected to attend the UofM, two of whom wanted to participate in Engineering. Similarly to the space camp, activities in the discovery camp were also intensive. Since our experience is limited at this stage, we shall describe details in the future. A new rendition of the camp is planned for the end of May 2014.

Another form to reach Indigenous students in Manitoba was the two-day Peguis First Nation Science, Technology and Engineering Symposium offered at the University of Manitoba in the past. It provided many presentations on research at the UofM, including major workshops on robotics.

\section{Concluding Remarks}

Although students should be storming the Engineering gates of universities, it is no so in practice. Although there are many socio-political reasons for this hesitation, one view is to help the students and their parents decide by exposing them to experiential learning. The Space Camp and the new Verna Kirkness Program Discovery Camp are attempts to help in that process.

At this stage, we have no hard evidence that these efforts have produced the desired increase in enrolment, but we know that the enrolment has been increasing over the last years. Exit interviews and evaluation forms by both the participants and their guardians indicate very positive experience and plans for the future. More specifically, the students indicated clearly that they had gained new understanding of the university, and the higher education they can receive. The forms have also been used to improve the camps each year. A side effect is the experience that all the instructors and TAs gain from this experiential learning.

\section{Acknowledgements}

We would like to thank the Department of Electrical and Computer Engineering and the Faculty of Engineering at the University of Manitoba for partial financial support of this project. Special thanks go to Barbara Bowen from the Manitoba Aerospace for their support throughout the years. We are grateful to all the volunteer instructors in the camps for their dedication and effort in making each camp a place to be.

\section{References}

[1] Witold Kinsner, M.G.(Ron) Britton, and Jeff Cieszecki, "Teaching teachers: Could I design, build and test a tiny smart robot?," in Proc. CEEA Canadian Engineering Education Conf., CEEC11 (St. John's, NL; 6-8 June 2011), 7 pp., 2011.

[2] Witold Kinsner, M.G. (Ron) Britton, Jeff Cieszecki, Wayne Ellis, Alan Thoren, Dario Schor, Brian Statham, Greg Linton, Tom Tessier, Rob Striemer, Colleen Flather, Barbara Bowen, and Norman Lee, "A space adventure camp and pre-university outreach," in Proc. CEEA Canadian Engineering Education Conf., CEEC11 (St. John's, NL; 6-8 June 2011), 8 pp., 2011.

[3] Witold Kinsner, M.D.(Ron) Britton, Dario Schor, Arash Fazel Darbandi, Kris Goodmanson, Cody Friesen, Emily Bashford, "Preliminary experience from the Canadian Satellite Design Challenge," in Proc. Can. Engineering Education Conf., CEEA11 (St. John's, NL; June 6-8, 2011) 6 pp., 2011.

[4] Witold Kinsner, Stephanie English, Curtis Einarson, Bryan Drobot, Kelly Riha, Mohamed Nasri, Rafi Belal, Barry Prentice, and Dale George, "Design of navigation subsystem for a new UAV: A composite of a capstone and research projects," in Proc. 5th Conference of the Canadian Engineering Education Association, CEEA 2014 (Canmore, AB; June 8-11, 2014). 


\section{APPENDIX A}
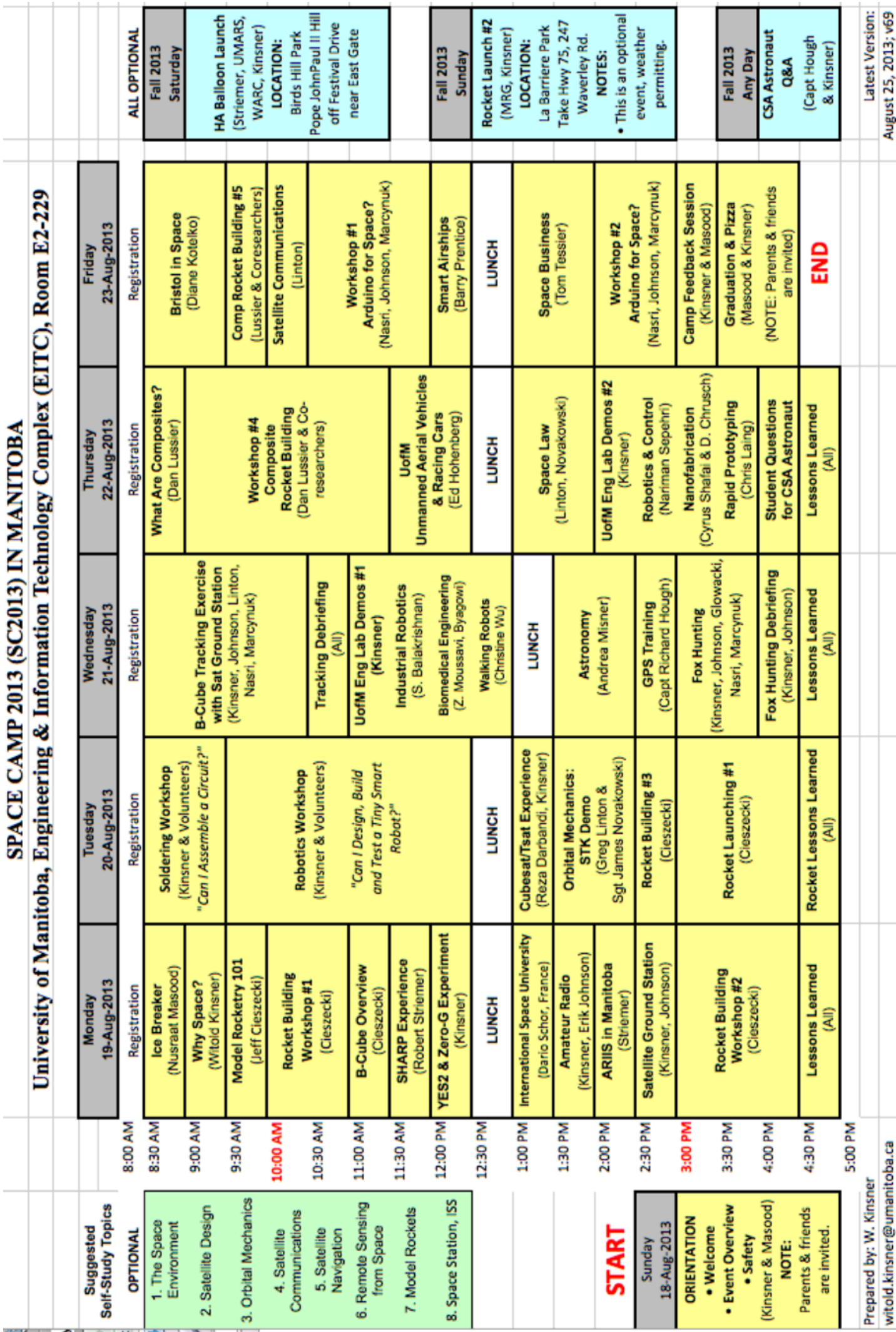